\title{
Merktrouw en merkwaardering
}

\author{
Dr. J.M.M. Bloemer
}

\section{Inleiding}

Merktrouw van consumenten betekent dat consumenten herhaalde malen hetzelfde merk kopen. Dit kan duiden op een hoge(re) merkwaardering en leiden tot meer omzet c.q. winst. Beide kunnen op de balans van een onderneming tot uitdrukking worden gebracht. Zo bezien is de merktrouw van consumenten niet alleen vanuit een marketing optiek van belang maar zeker ook vanuit een (in- en externe) berichtgevings- en accountancy optiek.

De belangrijkste doelstelling van dit artikel is aan te geven dat, indien een onderneming het wenselijk acht de waarde van het merk op de balans te activeren, bij de merkwaardering nadrukkelijk rekening moet worden gehouden met de soort merktrouw van de consument: ware merktrouw of herhalingsaankopen. Door middel van een actief beleid ten aanzien van het bevorderen van de merktrouw kan indirect de waarde van het merk op de balans, als immateriële activum, worden gestuurd. Op de wenselijkheid van het opnemen van de waarde van het merk wordt in dit artikel niet ingegaan.

Een tweede doelstelling van dit artikel is te tonen hoe merktrouw kan worden beïnloed via de tevredenheid van consumenten. Vaak wordt impliciet verondersteld dat naarmate de tevredenheid van consumenten toeneemt, ook de merktrouw groter wordt. Onderzoek heeft aangetoond dat er inderdaad een positieve relatie bestaat tussen deze twee concepten. Deze relatie is echter verre van perfect en blijkbaar worden bij de bestudering ervan een aantal belangrijke aspecten over het hoofd gezien. Op de eerste plaats wordt geen on- derscheid gemaakt tussen twee essentieel van elkaar verschillende soorten merktrouw (ware merktrouw en herhalingsaankopen). Op de tweede plaats wordt voorbijgegaan aan het feit dat tevredenheid op verschillende manieren kan ontstaan. Namelijk op basis van een weloverwogen evaluatie of op basis van een zekere impliciete acceptatie. Afhankelijk hiervan verschilt de invloed van tevredenheid (manifest of latent) op de merktrouw van consumenten.

In dit artikel wordt daarom tevens aandacht besteed aan een onderzoek naar de relatie tussen de tevredenheid met een merk en de trouw aan datzelfde merk. Dit ter ondersteuning van de stelling rekening te houden met de soort merktrouw bij de waardering van een merk. Bovendien wordt aangegeven hoe de soort merktrouw door een onderneming, via de tevredenheid van consumenten, kan worden beïnvloed.

Allereerst zal worden ingegaan op het onderscheid tussen ware merktrouw en herhalingsaankopen. Vervolgens wordt dit onderscheid in verband gebracht met de waardering van een merk op de balans. Daarna wordt aandacht besteed aan het onderscheid tussen manifeste en latente tevredenheid. Er volgt een uiteenzetting over de relatie tussen merktrouw en tevredenheid, welke door een empirisch onderzoek wordt ondersteund. Het artikel wordt afgesloten met conclusies en aanbevelingen ten aanzien van de consequenties van het onderscheid tussen ware merktrouw en herhalingsaankopen in relatie tot de waardering van een merk

Dr. José M.M. Bloemer studeerde economische psychologie aan de Katholieke Universiteit Brabant en is sinds 1987 verbonden aan de Rijksuniversiteit Limburg bij de sectie Marketing en Marktonderzoek. 


\section{Ware merktrouw en herhalingsaankopen}

Het is van belang twee soorten merktrouw te onderscheiden die, hoewel zij zich uiten in hetzelfde gedrag, toch van elkaar verschillen omdat de oorzaak van dat gedrag verschillend is: ware merktrouw en herhalingsaankopen (zie tevens Bloemer, 1990; Day, 1969, Engel et al. 1986).

Ware merktrouw uit zich in het herhaald kopen van een merk omdat de consument een binding heeft met het merk. Herhalingsaankopen uiten zich eveneens in het herhaald kopen van een merk, echter zonder dat hieraan een binding met het merk ten grondslag ligt. Deze herhalingsaankopen zijn gebaseerd op gewoontevorming of gemakzucht (Jacoby, 1971; Jacoby en Chestnut, 1978).
Ware merktrouw is in vergelijking met herhalingsaankopen een grotere garantie voor huidige en toekomstige afzet, omzet en winst (Aaker 1991). In termen van merkwaardering betekent dit dat een merk met een grote waarlijke trouwe aanhang een grotere waarde vertegenwoordigt dan een merk met een beperkte waarlijk trouwe aanhang of hooguit herhalingsaankopers. De waarde van het merk zoals daaraan uitdrukking wordt gegeven op de balans zou dus mede afhankelijk moeten zijn van de 'soort' merktrouw van de consumenten van het merk.

De 'interbrand technique' voor merkwaardering van Murphy (1990) biedt hiervoor directe aanknopingspunten en wordt daarom hier als uitgangspunt genomen. Andere bekende merkwaarderingsmethoden (zie hiervoor o.a.

Tabel 1: De factoren die de sterkte van een merk bepalen

\begin{tabular}{|c|c|c|}
\hline Factor & Naam & Toelichting \\
\hline 1 & Marktleiderschap & $\begin{array}{l}\text { Een marktleider is stabieler en waardevoller dan een } \\
\text { merk dat geen marktleider is. }\end{array}$ \\
\hline 2 & Stabiliteit & $\begin{array}{l}\text { Lang bestaande merken, met een grote mate van } \\
\text { merktrouw, zijn waardevoller dan nieuwe merken. }\end{array}$ \\
\hline 3 & Markt & $\begin{array}{l}\text { Merken in de voedsel- en drankindustrie zijn waar- } \\
\text { devoller dan merken in bijvoorbeeld de kleding- en } \\
\text { high-techindustrie. }\end{array}$ \\
\hline 4 & Internationalisering & $\begin{array}{l}\text { Internationale merken zijn waardevoller dan regio- } \\
\text { nale merken. }\end{array}$ \\
\hline 5 & Trends & $\begin{array}{l}\text { De lange termijn ontwikkeling van een merk is be- } \\
\text { langrijk omdat wordt verwacht dat deze ontwikke- } \\
\text { lingen zich voortzetten in de toekomst. }\end{array}$ \\
\hline 6 & Ondersteuning & $\begin{array}{l}\text { Een merk dat communicatief (o.a. door reclame) } \\
\text { goed wordt ondersteund is waardevoller dan een } \\
\text { merk dat minder goed wordt ondersteund. }\end{array}$ \\
\hline 7 & Bescherming & $\begin{array}{l}\text { Een goed beschermd merk (bijvoorbeeld door het } \\
\text { merkenrecht) is waardevoller dan een niet goed be- } \\
\text { schermd merk. }\end{array}$ \\
\hline
\end{tabular}


De Smeth, 1992) houden veelal in het geheel (nog) niet direct rekening met de merktrouw van consumenten. De 'interbrand technique' gaat ervan uit dat de waarde van een merk op de balans kan worden weergegeven als het produkt van de winstgevendheid van het merk en een vermenigvuldigingsfactor. Deze vermenigvuldigingsfactor brengt tot uitdrukking hoeveel maal de jaarlijkse winstgevendheid van het merk waard is, de zogenaamde sterkte van het merk. Deze factor kan worden bepaald op basis van een uitgebreide vragenlijst. Hierin komen zeven factoren aan de orde (zie Tabel 1). De vermenigvuldigingsfactor wordt uiteindelijk bepaald als de gewogen somscore over deze factoren. De relatie tussen de vermenigvuldigingsfactor en de sterkte van een merk wordt in Figuur 1 tot uitdrukking gebracht.

Eén van de factoren die bepalend is voor de hoogte van de vermenigvuldigingsfactor is de stabiliteit van de markt (zie Tabel 1). Voor een belangrijk deel wordt de stabiliteit van de markt bepaald door de merktrouw van de consumenten. Bij het vaststellen van de stabiliteit wordt echter geheel voorbij gegaan aan het onderscheid tussen ware merktrouw en herhalingsaankopen. Een markt met overwegend ware merktrouwe consumenten zal evenwel op termijn veel stabieler zal zijn en dus een hogere waardering verdienen dan een markt met overwegend herhalingsaankopers.

Figuur 1: De vermenigvuldigingsfactor

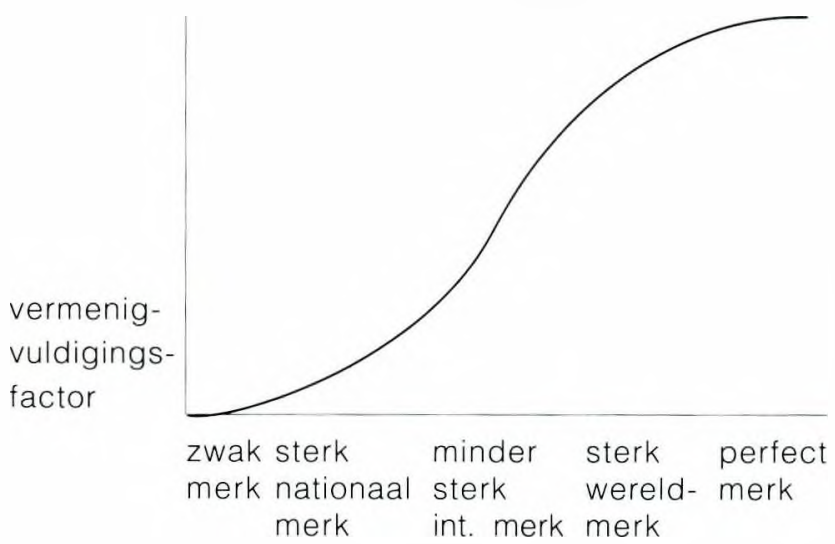

Nu het onderscheid tussen ware merktrouw en herhalingsaankopen is benadrukt en tevens is aangegeven waarom met name ware merktrouw van belang is bij de waardering van een merk, wordt nader ingegaan op het onderscheid tussen twee soorten tevredenheid: manifeste tevredenheid en latente tevredenheid. Beide soorten tevredenheid hebben een verschillende betekenis wanneer een onderneming de ware merktrouw van de consument wil stimuleren en hierdoor de merkwaardering wil beïnvloeden.

\section{Manifeste tevredenheid versus latente tevredenheid}

Niet alle tevredenheidsoordelen van consumenten zijn gelijk (Bloemer en Poiesz, 1989 tevens Bloemer, 1991). Consumenten kunnen merken uitgebreid of slechts marginaal evalueren (Day, 1977; Freedman, 1964; Jacoby, 1971; Swan en Trawick, 1979 en Engel et al, 1986). Wordt een merk uitgebreid geëvalueerd dan is er, bij een positieve evaluatie, sprake van manifeste tevredenheid. Dit betekent dat consumenten uitgebreid nagaan in welke opzichten een merk al dan niet aan de verwachtingen voldoet. Daarentegen is er sprake van latente tevredenheid indien een merk in het geheel niet of slechts marginaal wordt beoordeeld

Uitgangspunt hierbij is dat wanneer de consument voldoende gemotiveerd is en over voldoende capaciteit beschikt, een merk uitgebreid zal worden geëvalueerd (Petty et al. 1983). De consument wil en kan een merk uitgebreid beoordelen. Deze consumenten hebben een manifest tevredenheidsoordeel. Indien de consument niet voldoende gemotiveerd is en/of niet over voldoende kennis beschikt zal een merk slechts marginaal worden geëvalueerd. In dit geval hebben consumenten slechts een latent tevredenheidsoordeel omdat zij een merk niet uitgebreid willen en/of niet kunnen beoordelen. Dit latente tevredenheidsoordeel betekent niet meer dan een impliciete, tijdelijke acceptatie van het merk. 
De relatie tussen tevredenheid en merktrouw

Manifeste tevredenheid ontstaat doordat de consument een merk uitgebreid evalueert en dus een duidelijk expliciet tevredenheidsoordeel vormt. Dit tevredenheidsoordeel zal eenduidig van invloed zijn op het aankoopgedrag in de toekomst (vergelijk Elaboration Likelihood Model; Petty et al., 1983). Bovendien is te verwachten dat naarmate de manifeste tevredenheid toeneemt ook de binding met een merk zal toenemen. Hierdoor zal wanneer de manifeste tevredenheid met een merk toeneemt, ook de ware merktrouw toenemen.

Latente tevredenheid is daarentegen niet meer dan de impliciete acceptatie van een merk die niet op een uitgebreide evaluatie van een merk is gebaseerd. Latente tevredenheid zal daarom minder duidelijk dan manifeste tevredenheid van invloed zijn op het aankoopgedrag in de toekomst. Naarmate de latente tevredenheid toeneemt hoeft de binding met het merk in het geheel niet toe te nemen. Een stijging van de latente tevredenheid kan leiden tot een toename in de kans op een herhalingsaankoop, maar ondanks de latente tevredenheid kan even gemakkelijk van merk worden gewisseld.

Gezien het prominente belang van ware merktrouw bij de waardering van een merk staat dit concept in het nu volgende empirisch onderzoek centraal. De belangrijkste verwachting is dat manifeste tevredenheid een belangrijker bijdrage levert bij de verklaring van ware merktrouw dan latente tevredenheid (zie Figuur 2). Het onderzoek bevestigt de juistheid van deze verwachting.

Als consequentie zal een onderneming die de ware merktrouw van de consument wil stimu-

Figuur 2: De relatie tussen tevredenheid en merktrouw

\section{latente}

tevredenheid -.------> herhalingsaankopen

manifeste

tevredenheid ---------> ware merktrouw leren daarom met name aandacht moeten besteden aan de manifeste tevredenheid van de consument. Alvorens hierover concrete aanbevelingen te doen, wordt kort ingegaan op het empirisch onderzoek.

\section{Het empirisch onderzoek}

\section{Produkten}

Het empirisch onderzoek naar de relatie tussen tevredenheid en ware merktrouw is uitgevoerd met behulp van een schriftelijke vragenlijst. Deze heeft betrekking op twee produkten: onbespeelde cassettebandjes en haarshampoo.

\section{Operationalisatie van concepten}

Ware merktrouw wordt geoperationaliseerd als het produkt van de mate van binding met een merk en de kans op een herhalingsaankoop. De mate van binding wordt bepaald op basis van de somscore per respondent over de 6 verschillende 5-punts Likertschaal-items van de bindingsschaal. Deze schaal is in het vooronderzoek getest en betrouwbaar en valide bevonden. De kans op een herhalingsaankoop wordt uitgedrukt in de procentuele kans dat hetzelfde merk bij een volgende aankoop opnieuw zal worden gekocht. De mate van tevredenheid wordt eveneens in procenten gemeten.

Ontevreden respondenten worden in dit onderzoek buiten beschouwing gelaten omdat tevredenheid en niet ontevredenheid als antecedent van ware merktrouw centraal staat. Overigens geeft slechts $2 \%$ van de respondenten te kennen ontevreden te zijn met één van de beide produkten.

De soort tevredenheid, latent of manifest, wordt bepaald op basis van de motivatie en de capaciteit van de respondent om de merkkeuze te evalueren. Beide worden eveneens gemeten met behulp van een 5-punts Likertschaal welke uit respectievelijk 11 en 6 items bestaat. De somscore per respondent per schaal is 


\section{MAB}

bepalend voor de mate van motivatie en capaciteit. Respondenten die beschikken over een grote motivatie en capaciteit om de merkkeuze te evalueren worden geacht manifest tevreden te zijn. Respondenten die daarentegen niet beschikken over een grote motivatie en capaciteit om de merkkeuze te evalueren, worden verondersteld latent tevreden te zijn.

\section{Steekproef}

De vragenlijst is ingevuld door 838 consumenten. Deze steekproef is redelijk representatief qua leeftijd, beroep en grootte van het huishouden alsmede qua marktaandelen van de gekochte merken van de twee produkten. Gezien de doelstelling van het onderzoek, het inzicht verwerven in de relatie tussen tevredenheid en ware merktrouw, een acceptabele steekproef.

\section{Analyse en resultaten}

Om na te kunnen gaan of de sterkte van de relatie tussen tevredenheid en ware merktrouw afhankelijk is van de soort tevredenheid wordt voor twee subgroepen van respondenten (latent tevreden en manifest tevreden) de correlatiecoëfficiënt berekend tussen de mate van tevredenheid en de mate van ware merktrouw.

Tabel 2: Correlatie (pearson corr) tussen de mate van tevredenheid $(T)$ en de mate van ware merktrouw (MT) bij latent en manifest tevreden respondenten met cassettebandjes en haarshampoo

\begin{tabular}{lllll}
\hline & $\begin{array}{l}\text { Cassette- } \\
\text { bandjes }\end{array}$ & \multicolumn{2}{l}{$\begin{array}{l}\text { Haar- } \\
\text { shampoo }\end{array}$} \\
\hline respondenten & T-MT & $\mathrm{n}$ & T-MT & $\mathrm{n}$ \\
latent tevreden & .21 & 112 & $.29^{\star \star}$ & 183 \\
manifest tevreden & $48^{* *}$ & 135 & $50^{\star \star}$ & 180 \\
Fisher $Z$ & $2.38^{*}$ & & $2.27^{\star}$ & \\
\hline$p<.05 ;{ }^{\star \star}: p<.001$ & & & &
\end{tabular}

Indien de correlatiecoëfficiënten significant van elkaar verschillen kan geconcludeerd worden dat er inderdaad een verschil is tussen de relatie tussen latente tevredenheid en ware merktrouw en de relatie betreffende manifeste tevredenheid en ware merktrouw. De resultaten van deze analyse staan vermeld in Tabel 2

Uit Tabel 2 blijkt dat de relatie tussen de mate van tevredenheid en de mate van ware merktrouw inderdaad afhankelijk is van de soort tevredenheid. Dit betekent dat het een verschil maakt of respondenten manifest of latent tevreden zijn voor wat betreft de relatie tussen de mate van tevredenheid en de mate van ware merktrouw; manifest tevreden respondenten zijn vaker waarlijk merktrouw dan latent tevreden respondenten.

De sterke overeenkomst in de resultaten tussen onbespeelde cassettebandjes en haarshampoo is een duidelijke indicatie dat de relatie tussen tevredenheid en ware merktrouw niet produktspecifiek is. Deze relatie lijkt met name afhankelijk van de bereidheid van de consument om een merk uitgebreid te evalueren

\section{Conclusie}

Samenvattend kan gesteld worden dat de ware merktrouw van een consument met name kan worden gestimuleerd door er voor te zorgen dat de tevredenheid van een consument gebaseerd is op een uitgebreide merkevaluatie. Immers, manifeste tevredenheid leidt eerder tot ware merktrouw dan latente tevredenheid. Dit laatste geeft hooguit aanleiding tot herhalingsaankopen, maar leidt bijna net zo gemakkelijk tot het wisselen van merk.

Deze bevinding ligt tevens ten grondslag aan de belangrijkste theoretische implicaties van het onderzoek. Het is noodzakelijk, bij het toekennen van een waarde aan het merk op de balans, rekening te houden met de merktrouw van consumenten en daarbij tevens een duidelijk onderscheid te maken tussen ware merktrouw en herhalingsaankopen. Ware merktrouw 
verdient in dit verband een duidelijk hogere waardering dan herhalingsaankopen.

\section{Aanbevelingen}

De aanbevelingen die kunnen worden gedaan op basis van het theoretische en empirische onderzoek vallen in twee delen uiteen. Allereerst kunnen aanbevelingen worden gedaan welke direct betrekking hebben op het stimuleren van de manifeste tevredenheid van consumenten. Dit met het directe doel om de ware merktrouw te doen toenemen waardoor indirect de waardering van een merk kan worden beïnvloed. Op de tweede plaats kunnen aanbevelingen worden gedaan ten aanzien van het tot uitdrukking brengen van de soort merktrouw in de waardering van het merk op de balans.

\section{Het bevorderen van ware merktrouw}

Uit het empirisch onderzoek is gebleken dat de soort en de mate van tevredenheid belangrijk zijn bij het bewerkstelligen van ware merktrouw. Dit betekent dat ware merktrouw gestimuleerd kan worden door ervoor te zorgen dat de consument het gekozen merk zo uitgebreid mogelijk evalueert en uiteraard daarbij maximaal tevreden is. Dit betekent een zo groot mogelijke manifeste tevredenheid van de consument.

Om een zo uitgebreid en positief mogelijke evaluatie te bewerkstelligen dient een onderneming te benadrukken dat er duidelijke verschillen tussen merken bestaan en deze verschillen ook voor de consument duidelijk waarneembaar te maken (Assael, 1987). Dit vergroot zowel het willen als het kunnen evalueren van een merk door de consument. Diverse produktdifferentiatietactieken kunnen hierbij worden gehanteerd. Afhankelijk van het merk kan men in de communicatie aanhaken bij belangrijke onderwerpen (gezonaheid, milieu), persoonlijke situaties (met of zonder vrienden), waarden (vrede, geluk, gezelligheid) en normen (risico-mijdend versus risicovol).
Daarbij is het uiteraard belangrijk de sterke punten (produktvoordelen of benefits) van het eigen merk, eventueel in vergelijking tot andere merken, te benadrukken. Indien noodzakelijk moeten nieuwe onderscheidende merkvoordelen worden geïntroduceerd. Tevens dienen de voor de consument belangrijke merkvoordelen duideiijk en begrijpelijk te worden gecommuniceerd waarbij aansluiting moet worden gezocht bij de manier waarop de consument het merk evalueert.

\section{Merkwaardering}

Wanneer een onderneming van oordeel is dat haar waarde te laag wordt voorgesteld en zij in het bezit is van belangrijke merken, kan zij deze merken op de balans opvoeren. Dat wil zeggen dat immateriële merkrechten kunnen worden geactiveerd. Belangrijk voordeel is dat het eigen vermogen toeneemt. Belangrijk nadeel daarentegen is dat moeilijk objectief vast te stellen variabelen op de balans worden geïntroduceerd.

Het bepalen van de waarde van een merk is een subjectieve zaak. Volgens de 'interbrand technique' wordt een geschatte toekomstige jaarwinst (veelal een extrapolatie van het verleden) vermenigvuldigd met een factor die gebaseerd is op de sterkte van een merk. De bepaling van deze factor is sterk afhankelijk van subjectieve inzichten. De absolute waarde van een merk is, vanwege de subjectiviteit, minder belangrijk dan de verandering in die waarde, mits een bestendige gedragslijn bij de onderneming wordt gevolgd.

Nadere analyse van de factoren die de sterkte van een merk op de markt bepalen (waaronder merktrouw) kan daarom bijdragen tot het terugdringen van de subjectieve bepaling van de waarde van een merk.

Indien rekening wordt gehouden met verschillende soorten merktrouw, kan het relatief belang van de factor stabiliteit voor de vermenigvuldigingsfactor toenemen. Deze factor wordt daardoor namelijk een nog betrouwbaarder indicator van de sterkte van het merk. De score op de factor stabiliteit zou moeten toe- 


\section{MAB}

nemen naarmate het aandeel waarlijk merktrouwe consumenten toeneemt. Tot slot kan gesteld worden dat de stabiliteit van de markt alléén een factor is die moet worden meegenomen bij de bepaling van de waarde van een merk, indien daarbij de ware merktrouw van de consument als uitgangspunt wordt genomen. Door deze aanpassing zal de waarde die aan het merk wordt toegekend een nauwkeuriger afspiegeling vormen van de 'echte' waarde van het merk.

In dit artikel staat de 'interbrand technique' centraal. Deze techniek biedt directe aanknopingspunten tot het verdisconteren van ware merktrouw bij de merkwaardering omdat merktrouw als één van de bepalende factoren van de waarde van het merk wordt beschouwd. Andere merkwaarderingstechnieken beschouwen merktrouw niet altijd direct als een bepalende factor. Dit artikel pleit voor het verdisconteren van merktrouw in de waardering van een merk, waarbij een nadrukkelijk onderscheid tussen ware merktrouw en herhalingsaankopen noodzakelijk wordt geacht. Ware merktrouw verdient in dit verband een duidelijk hogere waardering dan herhalingsaankopen.

\section{Literatuur}

Aaker, D.A. (1991), Managing brand equity, The Free Press, New York.

Assael, H. (1987), Consumer Behavior and Marketing Action, Kent Publishing Company, Boston.

Bloemer, J.M.M. (1990), Herhalingsaankopen en merkentrouw, Tijdschrift voor Marketing, pp. 96-100

Bloemer, J.M.M. (1991), Problemen met tevredenheid, Tijdschrift voor Marketing, juli/augustus, pp. 8-15.
Bloemer, J.M.M. en Th.B.C. Poiesz (1989), The illusion of consumer satisfaction, Journal of Consumer Satisfaction, Dissatisfaction and Complaining Behavior, 2, pp. 43-48.

Day, G S. (1969), A two-dimensional concept of brand loyalty, Journal of Advertising Research, 9, pp. 29-35.

Day, R.L. (1977), The next step: commonly accepted constructs for satisfaction research, in: H.K Hunt (ed.) Conceptualization and Measurement of Consumer Satisfaction and Dissatisfaction. Cambridge, MA. Marketing Science Institute, pp. 153-183.

Engel, J.F., R.D. Blackwell en P.W. Miniard (1986), Consumer Behavior, The Dryden Press, Chicago.

Freedman, J.L. (1964), Involvement, discrepancy and change, Journal of Abnormal and Social Psychology. 69, pp. 290-295

Jacoby, J. (1971), Brand loyalty: a conceptual definition Proceedings American Psychological Association, 6, pp. 655-656.

Jacoby, J. en R.W. Chesnut (1978), Brand loyalty measurement and management, John Wiley and Sons. New York.

Murphy, J. (1990), Brand valuation - establishing a true and falr view, Century Hutchinson Ltd., London.

Petty, R.E., J.T Cacioppo en D. Schumann (1983), Central and peripheral routes to advertising effectiveness: the moderating role of involvement, Journal of Consumer Research, 10, pp. 135-146.

Smeth, F.F. de, (1992), Heeft elk merk het eeuwige leven? Een kernvraagstuk voor de waardering van merkrechten, Maandblad voor Accountancy en Bedriffseconomie, $1 / 2$, pp. $5-19$.

Swan, J.E. en I.F. Trawick (1979), Testing an extended concept of consumer satisfaction, in: R.L. Day en H.K. Hunt (eds.). New dimensions of consumer satisfaction and complaining behavior. Bloomington, IN. Indiana University Press, pp. 56-61.

\section{Noot}

Dit artikel is gebaseerd op het proefschrift 'Loyaliteit en Tevredenheid; een studie naar de relatie tussen merktrouw en consumententevredenheid' van mw. Dr. J.M.M. Bloemer, uitgegeven door de Universitaire Pers Maastricht (1993) en direct verkrijgbaar bij de auteur. 